\title{
AN AUTOMATED EXTERNAL DEFIBRILLATOR IN ROBOTICS AMBULANCE
}

\author{
Rohini S, Sneha C, Varshitha S, Yashodha G, Rohith H S and Bhagya M \\ Department of Electronics and Communication, \\ East West Institute of Technology, Bngalore, India
}

\begin{abstract}
The development of technology has brought up a significant change in almost every field and branch of science. As considered to the improvement of technology in terms of medical field various gadgets and robots are brought up. One such Robotic bestowment to the world is the AMBUBOT, Which focuses on the patients who at cases suffer from the Cardiac Arrest. Time is a critical issue when dealing with people who experience a sudden cardiac arrest as it could even lead the victim to death due to inaccessibility of the emergency treatment within the appropriate time. Hence, the AMBUBOT is preferred for an immediate treatment using Automated External Defibrillator (AED) to administer the victim within a few minutes after collapsing by facilitating various modes of operation from manual to autonomous functioning to save someone's life in the smart cities. Details, Design and Development of such robot is presented in this.
\end{abstract}

Keywords: ROBOT, Smart Healthcare, Smart Cities, Emergency Management, AED.

Cite this Article: Rohini S, Sneha C, Varshitha S, Yashodha G, Rohith H S and Bhagya M, an Automated External Defibrillator in Robotics Ambulance, International Journal of Electronics and Communication Engineering and Technology, 10(3), 2019, pp. 8-13. http://www.iaeme.com/IJECET/issues.asp?JType=IJECET\&VType=10\&IType=3

\section{INTRODUCTION}

Robot is an autonomous or semiautonomous machine that is capable to move around in their environment and also can perform various tasks either with direct or partial controls by human supervision or completely. Robotic systems are one of the key solutions for providing smart services. AMBUBOT is preferred for an immediate treatment using Automated External $\backslash$ Defibrillator (AED) to administer the victim within a few minutes after collapsing by facilitating various modes of operation from manual to autonomous functioning to save someone's life in the smart cities. The prototype with biomedical sensors is used for monitoring the patient health continuously. The location of the patient can also be tracked in case of emergency via GSM. The concept of high- tech machines that can serve the people well or relieve humans of tiresome chores has been an object of human imagination. It can be seen with many of today's occupations have been replaced by automation in order to help prevent manual handling injuries in the workplace. 
The smart world is expected to involve ubiquitous sensing, computing, and communication to achieve comprehensive interconnections of physical perception, cyber interaction, and social correlation. Increasing population density in urban environments demands adequate provision of services and infrastructure. This explosion in city population will present major challenges including air pollution, traffic congestion, health concerns, energy and waste management. As an emerging platform for that domain, a mobile robot can be employed in order to facilitate the health care operation as a smart operating vehicle in smart cities.

\section{OBJECTIVE}

The proposed ambulance robot for smart cities provides the service of ambulance with AED to help someone having a cardiac arrest. No need to wait for the ambulance to give first aid solutions. An emergency message and current position of victim will be generated. Message can be sent to the family members regarding current situation of the victim. It can be operated in auto or manual mode. To build more flexible structure such as Omni directional. To implement drone Robot partner this can fly in collaboration with the current system for faster performance in addition for operation in higher elevation. To implement autonomous robot.

\section{DESIGN METHODOLOGY}

\subsection{Brief Description}

During the time spent creating ambubot, we initially cantered around the robot development which must be moved in every one of the headings. Additionally, the model comprises of a microcontroller, through which the whole framework is mounted. At that point accompanies the sensors i.e., temperature sensor and heartbeat sensor that is mounted on the microcontroller through the drivers. Finally, it comprises of a LCD show. In this show framework enlisted specialists number will be shown, data about the patient's heart rate and body temperature will be shown and this data will be sent through the message for the recommended specialists number for a few minutes, with the goal that the specialist becomes more acquainted with about the patient's condition until the point when they achieve the healing centre. Later through the procedures it gives the messages that must be dealt with for the casualties.

The whole procedure will begin with a crisis application that will be produced for advanced mobile phones and requires the crisis rescue vehicle, through the GSM, it gives scope and longitude of the area and the message will be transmitted and gotten. Thus, it follows the area and achieves where the crisis is been called, with the medical aid pack and the unit comprises of paracetamol, cleaning powder, or arrangement, cotton, micropore tape and so on.

\subsection{BLOCK DIAGRAM}

Fig 1 showns the block diagram of AMBUBOT robot 


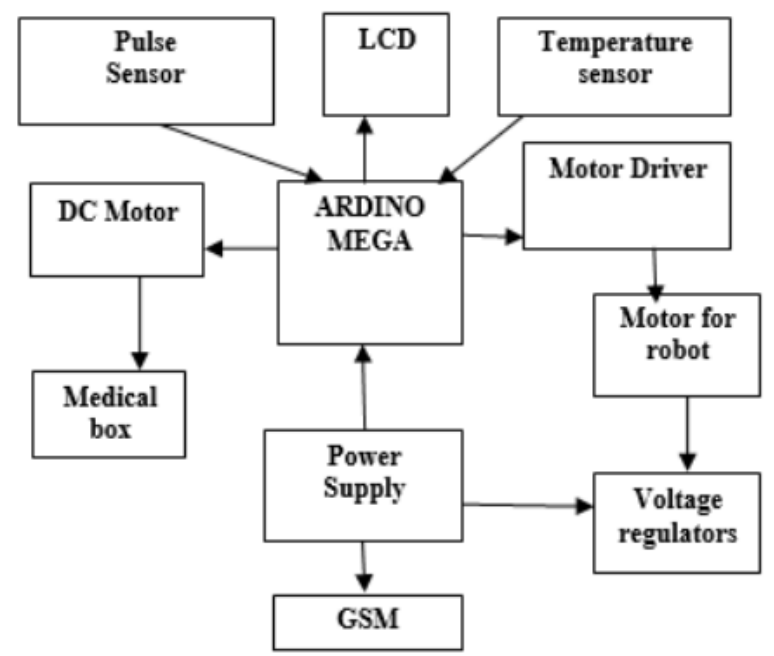

Figure 1 Block diagram of AMBUBOT robot

\subsection{Existing System}

AMBUBOT is not Omni directional. It only provides AED services in the ambulance \& it does not provide any first aid treatment for the patients. A smart vehicle for smart city can be implemented based on their architecture using simple sequences of three steps is Sense, Plan and Act.

\subsection{Proposed System}

The proposed ambulance robot for smart cities provides the service of ambulance with AED to help someone having a cardiac arrest. No need to wait for the ambulance to give first aid solutions. An emergency message and current position of victim will be generated. Also, the message can be sent to the family members regarding current situation of the victim. It performs time - consuming tasks. It can be operated in auto or manual mode. This section of our project has the Micro-controller part attached with the Motor relay and with the wheels of the robotic vehicle. The IR sensor along with the DC Battery is also observed in this section.

\subsection{Methodology}

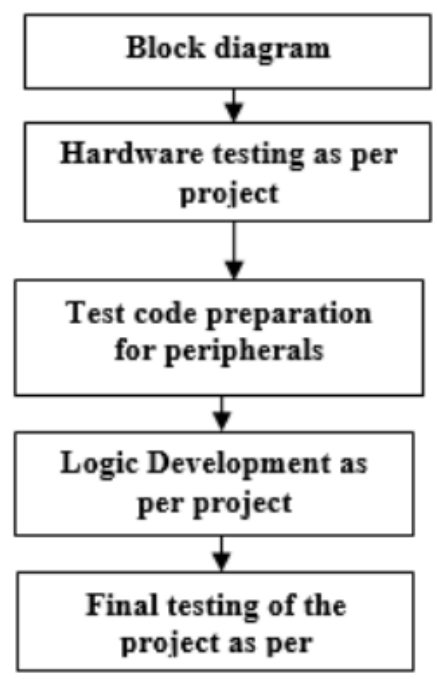

Figure 2 Methodology 


\subsection{Applications}

Robotic systems are one of the key solutions for providing smart services. AMBUBOT is preferred for an immediate treatment using Automated External Defibrillator (AED) to administer the victim. As an emerging platform for that domain, a mobile robot can be employed in order to facilitate the health care operation as a smart operating vehicle in smart cities. Reduce the human resources. Save precious time. Very safe to use.

\subsection{Advantages}

Easy to use. It saves time. Less man power required. An SMS sent to the nearest ambulance with GPS location about the patient. AMBUBOT reaches the patient location with defibrillators kit and provides first aid.

\section{HARDWARE}

a) Arduino Mega: Arduino Mega Microcontroller is used to implement the project. Microcontroller acts as a heart of the project which controls the whole system. It contains flash memory $256 \mathrm{~KB}$, SRAM $8 \mathrm{~KB}$, EEPROM $4 \mathrm{~KB}$ and it has high speed. On chip oscillation of $16 \mathrm{MHz}$.

b) Liquid Crystal Display (LCD): An LCD is considered to display all the output data at system and the operation that going on inside the microcontroller.

c) Pulse Sensor: Pulse sensor is to show the pulse rate of the person.

d) Power Supply: Power supply is used to supply power to electrical device.

e) Temperature Sensor: Temperature sensor is to show the temperature output of the person or surrounding environment.

f) GSM: GSM is used to send and receive the message.

g) Motor Driver: A motor driver is a little current amplifier; the function of motor drivers is to take a low-current control signal and then turn it into a higher-current signal that can drive a motor.

h) DC Motor: DC motor is used to convert electrical energy into mechanical energy.

i) Voltage Regulator: Voltage regulator is used to maintain a constant voltage level.

\section{SOFTWARE}

\subsection{Embedded C}

Embedded $\mathrm{C}$ is a set of language extensions for the $\mathrm{C}$ Programming language by the $\mathrm{C}$ Standards committee to address commonality issues that exist between $\mathrm{C}$ extensions for different embedded systems.

\section{RESULT}

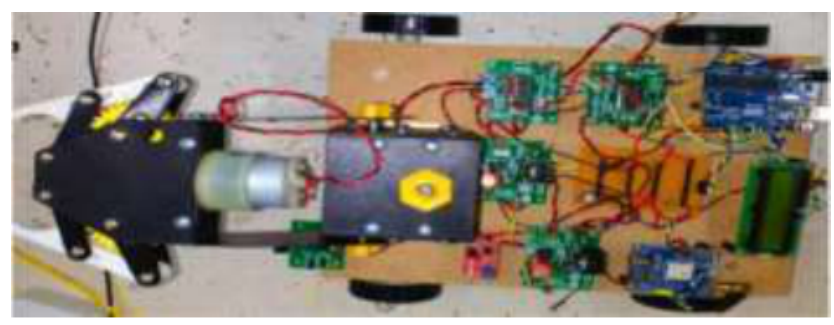

Figure 3 Prototype of the project 
The AMBUROBO ambulance measures the body temperature and heart rate of the victim and gives first aid to the victim if he /she is suffering from cardiac arrest.

\section{CONCLUSION}

Science is discovering or creating major breakthrough in various fields, and hence technology keeps changing from time to time. Going further, most of the units can be fabricated on a single along with microcontroller thus making the system compact there by making the existing system more effective. To make the system applicable for real time purposes components with greater range needs to be implemented. The proposed ambulance robot for smart cities provides the service of ambulance with AED to help someone having a cardiac arrest. Sudden cardiac arrest occurs when the heart has stopped beating effectively due to an electrical malfunction of the heart. This occurs instantly or shortly after symptoms appear. Early access to AED can be a life saving measure in the event of someone suffering a cardiac arrest.

\section{FUTURE SCOPE}

To have the absolute best chance of survival, immediate treatment must be carried out in the rest few minutes after someone collapses from a cardiac arrest. In this research, Ambubot was intended to improve on manual search assistance of ending AED with the help of the information technology so that an immediate treatment can be delivered to assist victims in cardiac arrest. The system which is Designed using structure modeling and is able to provide the desired result. It can be successfully implemented as a real time system with certain modifications. Science is discovering or creating major breakthrough in various fields, and hence technology keeps changing from time to time.

\section{REFERENCES}

[1] Eva Liu, Elyssa Wong. Emergency Ambulance Services. Research and Library Services Division Legislative Council Secretariat. June 1996.

[2] Kerber, Richard E; Becker, Lance B; Bourland, Joseph D; Cummins, Richard O; Hallstrom, Alfred P; Michos, Mary B; Nichol, Graham; Ornato, Joseph P; Thies, William H; White, Roger D; Zuckerman, Bram D (March 18, 1997). "Automatic External Defibrillators for Public Access Defibrillation". Circulation (American Heart Association) 95 (16771682):1677-82.

[3] Mohammad Arif, Hooman Samani, Chan-Yun Yang, and Yung-Yuan Chen, "Adaptation of mobile robot to intelligent vehicles," 2013 IEEE $4^{\text {th }}$ International Conference on Software Engineering and Service Science, Proceedings, pp.550-553, 23-25 May 2013.

[4] Casper, J.; Murphy, R.R., "Human-Robot Interactions during the Robot assisted urban search and rescue response at the World Trade Center," Systems, Man, and Cybernetics, Part B: Cybernetics, IEEE Transactions, Vol.33, No.3, pp.367, 385, June 2003.

[5] Matsuno, F.; Tadokoro, S., "Rescue Robots and Systems in Japan," Robotics and Biomimetics, 2004. ROBIO 2004. IEEE International Conference, pp.12-20, 22-26 Aug. 2004.

[6] Murphy, R.; Stover, S.; Pratt, K.; Griffin, C., "Cooperative Damage Inspection with Unmanned Surface Vehicle and Micro Unmanned Aerial Vehicle at Hurricane Wilma," Intelligent Robots and Systems, 2006 IEEE/RSJ International Conference on, pp.9, 9, Oct. 2006.

[7] The International Disaster Database, Centre for Research on the Epidemiology of Disasters - CRED

[8] Ho, Melissa, and Kevin Fall. "Poster: Delay tolerant networking for sensor networks." Proc. of IEEE Conference on Sensor and Ad Hoc Communications and Networks. 2004. 
Rohini S, Sneha C, Varshitha S, Yashodha G, Rohith H S and Bhagya M

[9] Ohno, K.; Kawatsuma, S.; Okada, T.; Takeuchi, E.; Higashi, K.; Tadokoro, S., "Robotic control vehicle for measuring radiation in Fukushima Daiichi Nuclear Power Plant," Safety, Security, and Rescue Robotics (SSRR), 2011 IEEE International Symposium, pp.38, 43, 15 Nov. 2011.

[10] Hayashi, T.; Kawamoto, H.; Sankai, Y., "Control method of robot suit HAL working as operator's muscle using biological and dynamical information," Intelligent Robots and Systems, 2005. (IROS 2005). 2005 IEEE/RSJ International Conference, pp.3063-3068, 2-6 Aug. 2005. 